\title{
Perineal Schwannoma: About One Case
}

\author{
K. Harou, Y. Ouldbenazzouz*, H. Boukhani, B. Fakhir, A. Aboulfalah, A. Soummani \\ Department of Gynecology and Obstetrics, UHC Mohamed VI, Marrakesh, Morocco \\ Email: *younesbenazzouz88@gmail.com
}

How to cite this paper: Harou, K., Ouldbenazzouz, Y., Boukhani, H., Fakhir, B., Aboulfalah, A. and Soummani, A. (2020) Perineal Schwannoma: About One Case. Open Access Library Journal, 7: e6146. https://doi.org/10.4236/oalib.1106146

Received: February 7, 2020

Accepted: March 6, 2020

Published: March 9, 2020

Copyright () 2020 by author(s) and Open Access Library Inc.

This work is licensed under the Creative

Commons Attribution International

License (CC BY 4.0).

http://creativecommons.org/licenses/by/4.0/

\begin{abstract}
Schwannoma is typically a benign tumor developed from Schwann cells of peripheral nerve sheath, although malignant cases have been reported [1]. We describe a 30-year-old patient who presented with a large perineal mass, close to the anal sphincter, whose complete excision revealed a perineal shwannoma. We also provide a discussion regarding the clinical, radiological and surgical features of this rare entity.
\end{abstract}

\section{Subject Areas}

Gynecology \& Obstetrics

\section{Keywords}

Perineal Schwannoma

\section{Introduction}

Schwannomas are a rare benign tumor arising from Schwann cells of the peripheral nerve sheath. It is most often located on the level of the cranial nerves and the posterior roots of the spinal nerves. The perineal localization is exceptional only a few cases have been reported in the literature; occurring preferentially in the third and fourth decades rather in men, with a sex ratio of 1.3 [1].

We report the case of a perineal schwannoma, of which we describe the clinical and radiological features as well as the surgical technique.

\section{Case Description}

30 -year-old patient, with no particular pathological history, 4 gesture 4 parity 4 living children, presented for pudendalgia associated to a perineal mass that the volume had increase gradually, without other associated signs. The clinical examination found a right lateral perineal mass of $2 \mathrm{~cm}$ molle, sensitive without any injury skin and the rest of the clinical examination was normal. A pelvic pe- 
rineal computed tomography was realized, describing a cystic perineal mass of 4 $\times 2 \mathrm{~cm}$ extended to the ischior rectal fossa. Surgical exploration by transperineal approach revealed a Latero-anal perineal mass of $4 \times 2 \times 2 \mathrm{~cm}$, with grayish aspect dotted by whitishs deposits in contact with the fibers of the external sphincter of the anus extending deeply into the ischio-rectal fossa. A complete excision was made sparing the fibers of the external sphincter of the anus. The postoperative suites were without particularities. The histopathological report revealed a proliferation of spindle cells having elongated or ovoid nuclei whose morphological aspect is in favor of a benign perineal schwannoma (Figure 1).

\section{Discussion}

Schwannomas are mostly benign tumors and have a very low rate of malignant transformation, their location is ubiquitous but most are located at the limbs, head and neck. Indeed, the perineal localization of schwannoma is very rare [2], which was in our case a source of difficulty diagnosis. Mostly they are an isolated and sporadic tumor. In $5 \%$ to $18 \%$ of cases, the lesions are multiple and are part of a neurofibromatosis type II [3]. Most schwannomas show a mutation or absence of the NF2 gene. The loss of the functionality of the NF2 protein would be necessary for the development of the tumor [4].

The symptomatology is mainly, poor and aspecific [5]. Clinically schwannoma can be manifested by localized pain, as in our case, by neurological symptom related to localization, or extrinsic compression linked to the size of the tumor. On computed tomography, schwannomas usually have an ovoid or spherical shape with well-defined border. In up to $61 \%$ of cases, they can present cystic changes as shown in the presented case. The MRI would be interesting to the extent that there is a well-encapsulated heterogeneous image with hypointensity on T1-weighted and hyperintensity on T2-weighted [5] [6]. MRI is also useful for analysing the tumor's relationships with adjacent structures in the perineum. Perineal schwannomas should be excised completely. The most difficult part of the case presented was the proximity of the anal sphincter. Careful dissection in such cases is mandatory to avoid injury to the sphincter muscle fibers and

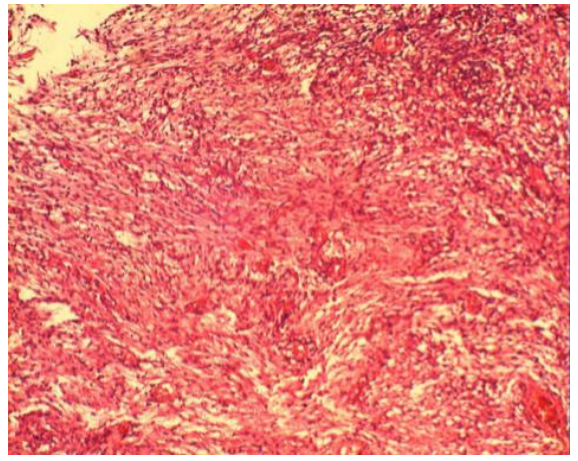

(a)

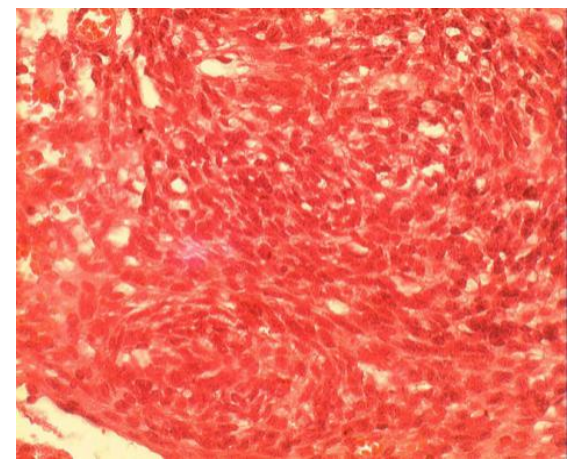

(b)

Figure 1. (a) (slide at 10× magnification); (b) (slide at 40× magnification): spindles cell tumor proliferation with intersecting beams. 
expose patients to the risk of incontinence. Some authors have advised partial resection to prevent injury to adjacent organs. However, recurrences are related to incomplete resections. Nevertheless, therapeutic abstention remains an option if the tumor is asymptomatic. The final diagnosis is made by histopathology that show the encapsulated aspect of the tumor in which one can find residual nerve fibers or axonal structures, its palisade organization of fusiform cells and especially the positivity of the protein S100 in immunohistochemistry. The search for genetic mutations of the NF2 gene isn't indicated in the absence of other schwannomas or family history [7].

\section{Conclusion}

Schwannoma is a rare tumor whose diagnosis is difficult because of the variability of the clinical and paraclinical presentation. Its treatment is surgical in case of patient discomfort or abstention with surveillance. It must be kept in mind that it can be integrated into neurofibromatosis type 2 .

\section{Conflicts of Interest}

The authors declare no conflicts of interest regarding the publication of this paper.

\section{References}

[1] Kransdorf, M.J. (1995) Benign Soft-Tissue Tumors in a Large Referral Population: Distribution of Specific Diagnoses by Age, Sex, and Location. American Journal of Roentgenology, 164, 395-402. https://doi.org/10.2214/ajr.164.2.7839977

[2] Hoaraua, N., Da Ines, D., et al. (2011) Retroperitoneal Schwannoma. Answer to December E-quid. Journal de Radiologie, 92, 70-73.

https://doi.org/10.1016/j.jradio.2010.11.002

[3] Maneschg, C., Rogatsch, H., Bartsch, G. and Stenzl, A. (2001) Treatment of Giant Ancient Pelvic Schwannoma. Techniques in Urology, 7, 296-298.

[4] Fass, G., Hossey, D., Nyst, M., Smets, D., Saligheh, E.N., Duttmann, R., Claes, K. and da Costa, P.M. (2007) Benign Retroperitoneal Schwannoma Presenting as Colitis: A Case Report. World Journal of Gastroenterology, 13, 5521-5524. https://doi.org/10.3748/wig.v13.i41.5521

[5] Majbar, A., Hrora, A., Jahid, A., Ahallat, M. and Raiss, M. (2016) Perineal Schwannome. BMC Research Notes, 9, 304. https://doi.org/10.1186/s13104-016-2108-1

[6] Hughes, M.J., Thomas, J.M., Fisher, C. and Moskovic, E.C. (2005) Imaging Features of Retroperitoneal and Pelvic Schwannomas. Clinical Radiology, 60, 886-893. https://doi.org/10.1016/i.crad.2005.01.016

[7] Ravier, E., Lopez, J.G., Augros, M., Romy, P. and Pugeat, G. (2011) Case Report and Review of the Literature: A Perineal Schwannoma. Progrès en Urologie, 21, 360-363. https://doi.org/10.1016/j.purol.2010.07.002 